\title{
Dois documentários e uma tese: rupturas no campo da produção e do consumo cultural
}

\section{Two documentaries and a thesis: ruptures in the field of cultural production and consumption}

Daniela Zanetti I Universidade Federal do Espírito Santo (UFES) Professora Adjunta do Departamento de Comunicação Social da (UFES), doutora em Comunicação e Cultura pela Universidade Federal da Bahia (UFBA).

\footnotetext{
Resumo

A partir da análise de dois documentários que tratam sobre o direito autoral e propriedade intelectual no contexto da cibercultura, o artigo coloca em evidência a disputa entre duas concepçôes de criação artística e de consumo cultural a partir do estabelecimento da cultura remix e da cultura do compartilhamento na Web. Palavras-Chave: Documentário, cultura remix, campo cultural.
}

\section{Abstract \\ From the analysis of two documentaries that deal with copyright and intellectual property in the context of cyberculture, the article highlights the struggle between two conceptions of artistic creation and cultural consumption from the establishment of remix culture and the culture of sharing on the Web.}

Keywords: Documentary, remix culture, cultural field. 


\section{Cultura remix e compartilhamento na base da produção e do consumo cultural}

O amplo debate sobre direitos autorais e propriedade intelectual no campo cultural, a "cultura remix" (LEMOS, 2005; BASTOS, 2007) e a produção de trabalhos artísticos colaborativos e/ou baseados na cópia, na remixagem, na apropriação, no sampler e no compartilhamento, que se ampliou e se evidenciou com o advento da cultura digital, tornou-se também tema de diversas obras audiovisuais, incluindo documentários. Trata-se de um discurso que se manifesta hoje de modo bastante enfático através dos próprios produtos culturais e suas formas de veiculação. O debate fortemente presente no início do século XXI em torno das consequências do compartilhamento online para os modos de consumo de músicas (CASTRO, 2005; 2006) e de obras audiovisuais, e sua consequente interferência na lógica de funcionamento das indústrias fonográfica e cinematográfica, traz à tona outro fenômeno que tem gerado debates em torno das formas de criação (ou de recriação) de objetos culturais. As trocas de músicas, vídeos e dos mais variados tipos de imagens são uma das práticas iniciais do processo de recriação artística contemporânea, que muitas vezes se utiliza dessa fragmentação imagética e informacional disponível na rede. Isso se deve, em parte, à segunda geração da Internet - a Web 2.0 - que se caracteriza, entre outros aspectos, por trazer uma nova arquitetura que possibilita aos usuários não apenas ter acesso a músicas, filmes, vídeos, imagens e textos, mas essencialmente produzi-los, redistribuí-los, avaliá-los, categorizá-los e recriá-los, de modo mais rápido e fácil (THOMPSON, 2008). Ampliando essas possibilidades, a cultura da convergência também transforma os processos de criação artística, consumo e agenciamento cultural, uma vez que desloca e fragmenta os centros de produção, considerando, por exemplo, o modo como se constituem as narrativas transmidiáticas (JENKINS, 2008).

Esse fenômeno também é base fundamental de um discurso que constitui uma das facetas do ciberativismo, qual seja a defesa do copyleft e novas formas de produção e distribuição de objetos culturais, em especial músicas, imagens e vídeos, que estão entre os principais tipos de conteúdo cultural e artístico que mais circulam na Web. No campo do audiovisual, além das obras de arte em si (virtuais, digitais, interativas), o documentário tem sido utilizado para compor narrativas em defesa de um discurso de redefinição das novas formas de produção artística e cultural. Diante deste cenário, este artigo examina dois documentários que discutem, a partir de estratégias distintas, o tema dos direitos autorais e da propriedade intelectual na contemporaneidade: A Remix Manifesto (2009) e Copiad, malditos! (2011), que trazem como tema o debate sobre direitos autorais e propriedade intelectual no campo da cultura a partir do advento das mídias digitais. Enquanto o primeiro explora mais o universo da produção musical, o segundo se dedica a refletir sobre a produção audiovisual. 
A escolha desses dois filmes levou em consideração algumas semelhanças entre eles, como o fato da própria obra servir de experimentação para a defesa do argumento principal (qual seja o questionamento da lógica dominante do copyright frente às mudanças promovidas pela cultura digital) e de terem sido disponibilizados no YouTube.

Parte-se de uma reflexão sobre a maneira como o discurso de legitimação das atuais práticas de criação artística e cultural se efetiva apresentando-se como sendo assumidamente resultado da apropriaçáo de outras obras e de sua livre circulação - o que contribui para a emergência de uma concepção de criação artística que relativiza a figura do autor, alterando as crenças já estabelecidas no campo artístico. Para tanto, utilizase o conceito de campo de Pierre Bourdieu (1990, 1996). Em seguida, apresenta-se uma breve análise dos dois documentários que compóem o objeto empírico. Objetiva-se com isso colocar em evidência a disputa entre concepçôes de criação artística no campo da música e do audiovisual e como este tema é transformado em tese nos filmes examinados. Parte-se do princípio de que há uma embate discursivo que coloca em xeque visôes geralmente antagônicas do processo artístico: uma que considera o fazer artístico fundamentado na originalidade e na autenticidade, e outro que se assume como fruto de um processo de permanente intertextualidade, de apropriaçóes de remixagens e também baseado em processos colaborativos.

Toma-se como pressuposto ainda a hibridização entre as artes e as comunicações, tanto no sentido da essência constitutiva dos produtos digitais (MANOVICH, 2001; SANTAELLA, 2003), quanto no sentido de que "os produtos da criação artística e da criação midiática não são mais tão facilmente distinguidos com clareza” (MACHADO, 2007, p. 23) - sem, todavia, desconsiderar as delimitaçóes desses dois campos. Essa hibridização decorre do fato do computador carregar a "contradição de aparecer como uma mídia única, sintetizadora de todas as demais" (MACHADO, 2007, p. 73). Uma das marcas da comunicação na atualidade é seu caráter híbrido e hipermidiático. Disso resulta o surgimento de narrativas múltiplas que circulam e atravessam uma série de produtos responsáveis pela cultura visual e informacional contemporânea (Manovich, 2001). Desse modo, o que se pretende não é se fixar no caráter artístico ou não dos materiais em circulação na Internet, mas sim na sua condição de conteúdo artístico transformado em objeto cultural circulante, considerando que o princípio que rege a cibercultura, segundo Lemos (2005), é a remixagem: "conjunto de práticas sociais e comunicacionais de combinaçôes, colagens, cut-up de informação a partir das tecnologias digitais" (LEMOS, 2005, p.1). Para Lemos, estão surgindo novos critérios de criação, criatividade e obra, que consolidam a cultura remix. Por remix, compreendem-se as "possibilidades de apropriação, desvios e criação livre (...) a partir de outros formatos, modalidades ou tecnologias, potencializados pelas características das ferramentas digitais e pela dinâmica da sociedade contemporânea" (2005, p. 2). Mais especificamente vinculado ao campo da criação artística, o conceito de remix se refere às "práticas 
em que a produção de sentido resulta da combinação de fragmentos" (BASTOS, 2007, p. 27), o que caracteriza a cultura contemporânea, e está associado à "forma mais contemporânea de polifonia e, por se tratar de processo possível apenas em mídias eletrônicas e digitais, é mais fluído" (id. ibid., p. 28).

É nesse contexto que se estabelece uma ruptura não somente com relação aos modos tradicionais de feitura das obras, mas também com relação à estrutura dos campos na qual estão inseridas, considerando a existência de uma disputa por legitimação de novas formas de criação cultura e artística baseadas na cultura remix. Um dos instrumentos de legitimação de diversas práticas sociais que caracterizam a cultura digital - e que muitas vezes funciona também como uma espécie de manifesto - é a produção de materiais audiovisuais, exemplificados pelas duas obras estudadas.

\section{O campo como lugar de disputas simbólicas}

A teoria dos campos tem como gênese as análises sociológicas empreendidas por Bourdieu a respeito dos campos literário e artístico, tendo como objetivo, entre outros aspectos, descrever e definir de que forma se revestem os mecanismos e os conceitos gerais de cada campo, objetivando compreender sua constituição e o que configura suas crenças internas e os mecanismos que lhe dão sustentaçáo, o jogo de linguagem que o caracteriza e os aspectos materiais e simbólicos em evidência.

Em As regras da Arte, Bourdieu defende que as instâncias de produção das obras literárias são passíveis de serem analisadas do ponto de vista sociológico, havendo, portanto, a possibilidade de se "compreender a gênese social do campo literário, da crença que o sustenta, do jogo de linguagem que aí se joga, dos interesses e das apostas materiais ou simbólicas que aí se engendram" (BOURDIEU, 1996:15). Para dar sustentação à sua teoria, o autor elabora o conceito de campo social.

O campo é entendido como "o espaço das relaçôes de força entre agentes ou instituiçóes que têm em comum possuir o capital necessário para ocupar posiçôes dominantes nos diferentes campos" (BOURDIEU, 1996, p. 244). É o espaço estruturado de posiçôes e suas inter-relações, que são determinadas pela distribuição de diferentes tipos de recursos ou capitais, espécie de "poderes sociais" adquiridos. Os capitais fundamentais são o econômico, o cultural e o simbólico, sendo que o simbólico é a "forma de que se revestem as diferentes espécies de capital quando percebidas e reconhecidas como legítimas" (BOURDIEU, 1990, p. 154). A partir da noção de capital, revela-se uma ambiguidade característica do universo da arte e que explicaria o modo como se dão os processos de entrada ou inclusão de novos atores no campo, que é, portanto, o lugar de embate de forças, de lutas simbólicas, entre os que possuem determinados tipos de capital (social, econômico, cultural). A noção de campo neste estudo ajuda a compreender como as culturas do remix e do compartilhamento no contexto da cultura digital representa um conjunto de saberes e práticas sociais (capitais cultural e social) que vai aos poucos 
favorecendo as rupturas e as disputas por legitimidade nos processos de criação artística, colocando de um lado os agentes e as instituiçôes tradicionais e, de outro, os novos agentes filiados à "vanguarda digital".

Cada campo possui uma forma particular de regulação das práticas e das representaçôes que impóe, e oferece aos agentes "uma forma legítima de realizaçáo de seus desejos, baseada em uma forma particular de illusio" (BOURDIEU, 1996, p. 259). A illusio, que possibilita a organização interna do campo, se caracteriza por ser um conjunto de crenças partilhadas pelos seus agentes. É a identificação de tais crenças que se objetiva com a análise dos documentários em foco, pois parte-se do pressuposto de que o argumento que defendem contribuem para disseminar novas concepçóes a respeito dos processos criativos e, assim, acirrar as disputas no campo da produção artística e do consumo cultural.

\section{O documentário como organização discursiva}

Segundo Nichols (1991), como qualquer outro discurso do real, o documentário conserva um vestígio de responsabilidade em descrever e interpretar o mundo da experiência coletiva. A idéia é alcançar, dominar um argumento em relação ao mundo histórico. Nesse processo, sons e imagens criam um vínculo com o mundo que compartilhamos. Os documentários, assim como as ficções, também fazem uso de recursos e programas de efeitos específicos para se garantir uma linha narrativa coerente e a atenção do público, mas a partir de uma lógica distinta: enquanto no documentário a narrativa se desenvolve no sentido de sustentar um argumento em relação ao mundo real, na ficção a narrativa está atrelada à configuração espaço-temporal da trama. (NICHOLS, 1991; 2005; RAMOS, 2008). O papel do documentário é fazer asserçōes, construir argumentos e pontos de vista sobre este mundo sócio-histórico e, para tanto, também utiliza cenários e personagens, ainda que estes pertençam a uma dimensão do mundo concreto. Os personagens são tratados como atores sociais. Contrariando a crença no predomínio dos "acasos" em documentários, este gênero normalmente envolve algum tipo de encenação, que pode ser: i) totalmente construída "artificialmente" e descolada do espaço fílmico; ii) realizada no mesmo espaço da locação e articulada com o sistema que rege o contexto retratado, mas dedicada a absorver a indeterminação oferecida pelas circunstâncias; iii) ou ainda baseada numa completa integração entre o espaço fora-de-campo e o espaço fílmico, a partir da qual (re)constrói atitudes dos atores sociais retratados condizentes com seus comportamentos cotidianos e habituais (RAMOS, 2008). No caso dos documentários analisados, espaço fílmico e espaço extra-diegético estão integrados: busca-se retratar as açóes e os processos nos quais os próprios realizadores estão envolvidos, e que estão relacionados com seus posicionamentos frente à questão central em jogo, qual seja a produçáo e o consumo de bens culturais no contexto da cultura digital.

O cinema documentário obtém uma forma de continuidade específica a partir da própria história do mundo real. "As situaçôes estão relacionadas no tempo e no espaço em virtude não da montagem, mas de suas ligaçóes reais, históricas" (NICHOLS, 2005:56). O documentário, antes der tudo, 
é definido pela intenção social do autor, que se manifesta nos elementos de indexação na escrita do filme (RAMOS, 2008), e seu ponto de vista tem relaçấo direta com a voz que emerge da obra. O texto é o material fílmico em si, e diz respeito aos modos de representação que, em última instância, são formas de organização dos textos em relação a certas características recorrentes ou convençôes. Um modo de representação envolve, por exemplo, questóes de autoridade e de credibilidade do discurso. Segundo Nichols (1991), elementos de narrativa, como uma forma particular de discurso, e aspectos do realismo, como um estilo representacional, informam a lógica do documentário e a economia do texto. Com relação ao espectador, o tipo de envolvimento é distinto, pois ao assistir um documentário o espectador pressupóe ser capaz tanto de crer no vínculo indexador entre o que está sendo visto e o que ocorreu diante da câmera, como de avaliar as intervençôes poéticas ou retóricas sobre essa representação da realidade a partir da perspectiva adotada na obra.

Como será visto, os documentários em foco se utilizam de diferentes estratégias narrativas para tratarem de um tema semelhante. Enquanto Rip, a remix manifesto faz amplo uso de imagens de diferentes tipos e origens, combinadas de modo a dar sentido a um discurso de defesa da cultura remix - que é aplicada na própria construção da obra -, Copiad Malditos! possui uma narrativa mais linear e dispositivos que proporcionam maior didatismo, considerando que seus realizadores querem demonstrar uma tese a partir do desafio colocado na própria instância de produção. Em comum, trazem fortes características dos chamados documentários expositivos, enfatizando a impressão de objetividade e de argumento bem embasado. Por isso, dependem muito de uma "lógica informativa transmitida verbalmente" e as imagens em geral "ilustram, esclarecem, evocam ou contrapóem o que é dito” (NICHOLS, 2005:143).

\section{Manifesto e demonstração}

O tom abertamente político e panfletário, com discursos de ataque às regras de copyright, é a marca de RIP! A Remix Manifesto (2009, 86 minutos) ${ }^{1}$, do documentarista e web-ativista canadense Brett Gaylor. O filme se baseia na tese do remix como instrumento revolucionário no campo da produção cultural, defendendo a ideia de que "a produção do novo se faz a partir do velho". Para ilustrar essa ideia, o diretor do filme usa como ponto de partida a atuação do artista Girl Talk, músico norteamericano que se tornou famoso no começo dos anos 2000 pela criaçáo de samplers e mashups (músicas produzidas a partir de fragmentos de outras músicas). Girl Talk - que o narrador-diretor chama de seu "artista favorito" - é o exemplo concreto utilizado para dar início à questão central do documentário: a crítica ao sistema de controle do consumo de bens culturais, em especial obras musicais, no contexto da cultura digital. Como aponta o título, o documentário toma a forma de um manifesto, sendo que a narrativa é organizada a partir dos quatro princípios que regem o "manifesto da remixagem": 1) A cultura sempre se constrói 
baseada no passado; 2) o passado sempre tenta controlar o futuro; 3) o futuro está se tornando menos livre; e 4) para construir sociedades livres é preciso limitar o controle do passado.

Nesta obra, a voz over é uma constante e mantém o viés retórico na maior parte do tempo. É sabido que, muito embora nem sempre a voz over condutora, ou do narrador, coincida com a voz do autor/diretor da obra, neste filme pode-se afirmar que a figura do narrador coincide com a do diretor, que também aparece em algumas cenas atuando como agente inserido no contexto histórico, personagem também afetado por esse contexto, algumas vezes explicitando parte do processo de produçáo de seu documentário. Numa das sequências, Brett Gaylor conversa com uma especialista em registro de copyrights e pergunta se ela quer ver como se faz um mashup. Com um laptop, Gaylor mostra a ela um vídeo de Girl Talk manipulando um programa de computador para produzir músicas a partir de fragmentos de outras. Em outro momento, explica a um advogado militante, favorável à flexibilização das leis de copyright, quais suas intençôes com o documentário e como pretendia reunir fragmentos de sons e imagens de terceiros para compô-lo. Mas a voz do narrador-diretor não se mantém presente ao longo de toda a obra. Devido à própria natureza estética do documentário, que se caracteriza pela colagem de imagens e sons provenientes de diversas fontes - material de arquivo, da Internet, etc. - em diversos momentos a voz over náo coincide com a do narrador. Contudo, não se deve confundir essa "voz" concreta, audível, com a chamada "voz do documentário" que, em síntese, representa a maneira de "expressar um argumento ou uma perspectiva” (NICHOLS, 2005, p. 73).

A introdução do filme, de quase cinco minutos, traz nas primeiras imagens, a inserção de grafismos típicos de uma interface gráfica de computador, que interagem com os créditos da obra. As imagens da sequência inicial mostram trechos de disputados shows de Girl Talk que, no palco, se apresenta apenas manipulando um computador. vO narrador-diretor, em voz over, diz que Girl Talk é seu artista preferido: "As notas que ele toca vêm de milhares de clássicos do rock, cortados e rearranjados para criar músicas novas". Em seguida, o próprio Girl Talk dá um depoimento sobre seu trabalho, questionando a forma como os artistas do mundo pop e suas músicas são tratados como objetos “intocáveis”, e que a possibilidade de manipular esses clássicos do mundo pop corresponderia a uma atitude transgressora.

O narrador-diretor retoma sua fala:

Não estamos discutindo se a música é original ou não. Este não é o ponto, pois as regras deste jogo não dependem de quem a compôs, mas de quem detém os diretos autorais.(...) $\mathrm{O}$ fato de haver pessoas chamando meu artista preferido de criminoso foi exatamente a razão que me levou a fazer este filme. Este filme é sobre uma guerra. Uma guerra pelas ideias. O campo de batalha é a Internet. E eu levo para o lado pessoal, pois nasci junto com a Internet. (RIP! A Remix Manifesto, 2009). 
Pela voz de condução do documentário, as referências a esta nova forma de criação musical são sempre relacionadas a uma ato subversivo: "As margens estéticas e ilegais da música", "downloads ilegais", "furtos de sons". A partir disso, são criadas as bases para a caracterização de um cenário no qual se desenrola uma batalha por modos de criação e legitimação artística. A partir da voz do narrador-diretor, o documentário assume uma posição ao mesmo tempo de defesa de uma determinada atitude "subversiva" no campo da arte e da produção cultural, e de ataque a seus "inimigos", de clara oposição aos "outros", aqueles que representam o passado, ou seja, as "pessoas que possuem a cultura que remixamos", que "não enxergam a grande biblioteca, a via expressa da informação", e para quem "ideias são propriedade intelectual”. O narrador enfatiza que desse lado está o copyright, em oposição aos que estão do outro lado e que querem "compartilhar ideias", os que representam o copyleft, aqueles que "acreditam que o domínio público deve ser protegido para garantir a troca de ideias e o futuro da arte e da cultura". Em seguida, o diretor do filme, Brett Gaylor, mantendo a voz over, afirma que viajou o mundo para encontrar esses representantes da cultura copyleft e que, juntos, elaboraram o "manifesto da remixagem". Ao longo de toda a narrativa, o diretor tenta provar que a criação a partir da cópia pode ser legítima, apresentando casos bem-sucedidos de iniciativas - inclusive no Brasil - de ruptura com o sistema de copyright.

Além de entrevistas e depoimentos, o documentário é, em grande parte, composto por um conjunto de imagens dos mais variados estilos e origens: trechos de programas de TV, noticiários, filmes, videoclipes, vídeos da Internet, além de fotografias e animaçôes. Em geral, essas sequências servem de base e de aparato imagético para dar sustentação à perspectiva da obra. Embora Girl Talk seja o artista-ícone escolhido como protagonista inicial do documentário, Rip! A Remix Manifesto é centrado na figura de seu diretor que, ao defender a tese da remixagem na produção cultural contemporânea, aponta para uma disputa de forças no campo artístico.

A realização de um documentário e sua posterior exibição e veiculaçáo na Internet utilizando uma licença copyleft é o mote da obra ¡Copiad, malditos! (2011, 57 minutos), do espanhol Stéphane Grueso. É o primeiro documentário exibido pela RTVE (Radio y Televisión Española) com licença Creative Commons e, por isso, está disponível para download ${ }^{2}$ ou pode ser assistido integralmente no Youtube ${ }^{3}$. O filme trata das questóes morais e éticas que envolvem o debate da propriedade intelectual na atualidade e a sua relaçáo com a cultura digital, enfatizando as diferenças entre os conceitos de copyright e copyleft.

Trata-se de um documentário com viés didático, que cumpre dois objetivos: i) expor uma tese-a de que o tema do direito autoral e da propriedade intelectual permeiam o contexto da cultura digital e, portanto, dizem respeito a todos de modo geral, havendo a necessidade de repensar novos modelos de negócio para os objetos culturais na contemporaneidade -, e ii) apresentar o processo de produção do próprio documentário a partir dessas questôes, na tentativa de atribuí-lo uma licença copyleft e disponibilizá-lo na Web. Ao 
longo da narrativa, o diretor também é um dos protagonistas. Ele aparece em várias cenas entrevistando especialistas sobre o tema, além de ser também o narrador, que ao longo do vídeo vai relatando os passos seguidos pela equipe para a realização do documentário e para tentar descobrir a melhor maneira de licenciar a própria obra em processo.

$\mathrm{Na}$ introdução do filme, são inseridos fragmentos de alguns depoimentos de especialistas no assunto, já anunciando o conflito que marcará a narrativa: "Creio que copiar significa não ter imaginação"; "Copiar é o contrário de criar”; "Para mim, copiar é multiplicar, e copiar é bom”; "Para mim, copiar significa a gênese da criação". Dentre os entrevistados, estão representantes institucionais, profissionais do mercado, escritores, advogados, ativistas.

$\mathrm{Na}$ sequência seguinte, o cenário passa a ser a pequena cidade de Montijo, no interior da Espanha, que servirá como exemplo de "espaço de resistência" frente às tentativas da SGAE (uma instituição que corresponderia à ECAD no Brasil) de controlar as emissóes musicais em ambientes públicos em defesa dos direitos autorais dos artistas. Para ilustrar a ação da SGAE, são exibidos depoimentos de proprietários de estabelecimentos comerciais da região que já haviam recebido comunicados da organização alertando sobre a veiculação pública irregular de músicas nesses espaços.

Em voz off, o diretor Stéphane Grueso dá início a sua argumentação: "Está claro que a propriedade intelectual e os direitos de autor estão presentes em nosso cotidiano". Em seguida, Grueso aparece em uma sala, ao lado de uma mesa com computadores, explicitando os objetivos de seu trabalho: "Nosso projeto consta deste documentário e de um blog, onde vamos narrar o desenvolvimento da produção e colocar as entrevistas na íntegra”. A ideia, segundo o diretor, é tentar lançar o documentário com uma licença distinta de copyright, de modo que seja permitido lançar o filme na Internet para ser assistido, compartilhado e baixado livremente. Ele diz, por fim: "Vamos ver se conseguimos".

No que se poderia chamar de segunda parte do filme, é inserida uma animaçáo que explica ao espectador o conceito de propriedade intelectual, de direitos do autor e de copyright, suas origens e transformaçôes ao longo da história. Mostra também como foi sendo ampliada a duração de copyright na medida em que foram surgindo novos meios de comunicação massivos e dispositivos de reprodutibilidade técnica de bens culturais. A animação apenas ilustra o que a voz over vai pontuando. Somente na última afirmativa, nota-se um claro posicionamento do documentário ao estabelecer um vínculo entre a última ampliação do período de copyright, de 1998, e o momento em que o personagem Mickey Mouse, da Walt Disney, passaria para o domínio público. A voz over se refere a ele como "un conocido ratón estaduniense".

$\mathrm{Na}$ passagem para a sequência seguinte, a imagem de um trem cruzando a paisagem e a fachada de uma universidade ilustra a ida do diretor a Barcelona, onde irá entrevistar o professor Ignasi Labastida, um dos representantes do Creative Commons na Espanha. Ele irá explicar os distintos 
tipos de licença que existem de modo a ajudar o diretor a escolher a licença mais adequada para seu filme. De volta a Madri, o diretor se encontra com um advogado especialista em propriedade intelectual, que lhe explica, desenhando um diagrama, quais os distintos tipos de direitos existentes numa produção audiovisual e o que é preciso fazer para torná-la disponível na Internet. Esmiuçando as várias partes do diagrama, o diretor do filme se vê diante de um desafio, pois percebe que para conseguir sua licença Creative Commons precisará cumprir certas exigências, entre as quais conseguir a permissão do uso de imagem de todos os entrevistados e também um acordo com a emissora, produtores e proprietários do documentário. Na parte seguinte, a voz over do narrador-diretor apresenta o cenário comunicacional atual e o aumento das práticas de troca de arquivos na rede, a pirataria e o surgimento de novos negócios para a comercializaçáo de artefatos culturais, afirmando ainda que o cinema é o setor mais afetado por este fenômeno. Em várias passagens, a narração explica os passos da produção do documentário e a negociação com diferentes agentes envolvidos no processo.

$\mathrm{Na}$ última parte do documentário, há novamente uma sucessão de opiniôes de especialistas que se contrapóem em relação ao modo como a Internet alterou o consumo de bens simbólicos. Mas o desfecho é dado pelo diretor, que continua conduzindo a voz da narrativa. Ele aparece no vídeo em seguida, em plano médio, informando que o objetivo da equipe foi atingido e que de acordo com a RTVE o filme será licenciado com Creative Commons e, portanto, disponibilizado na Internet, onde poderá inclusive ser baixado e compartilhado. Grueso enfatiza que, "neste momento e neste caso", a opção por este tipo de licenciamento foi muito mais pertinente do que proteger o filme com o copyright. Sua fala se mantém em voz off - de fundo, são exibidas imagens de pessoas numa livraria - defendendo a ideia de que sempre haverá um autor e um expectador e que a cultura manterá sua dinâmica de funcionamento, mas que as leis de propriedade intelectual devem se tornar mais flexíveis e se atualizarem com o tempo: "As chamadas indústria culturais e os intermediários estão se alterando ao longo da história, e agora com a Internet, realizam uma nova revolução. Temos que entender que as coisas podem mudar, decrescer, evoluir e inclusive desaparecer. E isso não é algo necessariamente mal”, conclui.

Copiad Malditos! se caracteriza por alguns elementos que contribuem para enfatizar a impressão de objetividade: um conjunto de entrevistas com especialistas; comentários do narrador-diretor, que são direcionados ao espectador; em geral, imagens que ilustram o que está sendo falado; animaçóes explicativas; e um tipo de edição que privilegia a continuidade retórica. Com base nessa estrutura, o documentário reúne depoimentos bastante favoráveis a uma readequação das leis de direitos autorais e de propriedade intelectual, colocando em evidência não somente a fala de especialistas, mas também iniciativas bem-sucedidas - inclusive de mercado - que procuram se adequar às transformaçóes das formas de produção e consumo de obras culturais. Os depoimentos que de certo modo defendem posicionamentos contrários a uma mudança nas regras atuais, servem não 
somente como contraponto, mas também revelam as barreiras econômicas e institucionais que não podem ser eliminadas tão facilmente, ou tão rapidamente, como desejam os mais entusiastas.

No que se refere à forma, em comum esses dois filmes trazem animaçóes explicativas, conduçáo por meio da voz do narrador-diretor, referência aos objetivos e aos processos de produção dos próprios documentários, entrevistas com especialistas e a utilização de plataformas online como ferramenta auxiliar na produção. Na dimensão discursiva, outro aspecto encontrado nos dois documentários é o estabelecimento de uma clara oposição entre defensores de uma nova concepção de arte e de produçáo cultural, e uma estrutura formal vigente que prescreve normas e constrangimento aos processos de criação, produção e consumo de objetos artísticos e culturais na contemporaneidade.

\section{A cibercultura remix como desencadeadora de disputas no campo cultural}

É notória a tentativa dos realizadores dessas duas narrativas audiovisuais de aplicar às obras aspectos que ilustrem o discurso no qual se baseiam, salientando a confluência entre as dimensôes inerentes à obra, suas condiçôes de produção e o contexto no qual são criadas.

Considerando que o campo é o lugar de embate de forças, de lutas simbólicas, entre os que possuem determinados tipos de capital, podese concluir o quanto a emergência de novas tecnologias de comunicação e informação possibilitaram a efetivação de um discurso duplo sobre divisões simbólicas: i) um que exalta a convergência entre as artes e as mídias de comunicação, eliminando as fronteiras entre esses dois campos sociais e rearranjando elementos tradicionalmente distintivos de objetos artísticos e midiáticos; ii) e outro que cria um abismo entre dois subcampos do campo artístico e cultural, estabelecendo relações de confronto entre um modelo "antigo" de criar e produzir objetos culturais e um modelo "novo", baseado na defesa das reapropriaçóes e do remix no processo criativo. Nesse lugar, os agentes que detém um tipo de capital simbólico - social e cultural calcado nas novas tecnologias náo somente têm a possibilidade de criar suas próprias obras a partir desse "novo" modelo - mais "livre", desvinculado das estruturas de poder e desapegado do capital econômico - , como também de criar outros espaços e mecanismos de reconhecimento e de consagração no campo artístico, estimulando inclusive o surgimento de novos públicos.

Como afirma Bourdieu em relação às lutas no campo das artes pela imposição "das categorias de percepção e de apreciação legítimas" (1996, p. 181), trata-se de uma disputa "entre os dominantes que pactuam com a continuidade, a identidade, a reprodução, e os dominados, os recém-chegados, que tem interesse na descontinuidade, na ruptura, na diferença, na revoluçáo”. Desse modo, "marcar época é, inseparavelmente, fazer existir uma nova posição para além das posiçóes estabelecidas, na dianteira dessas posiçóes, na vanguarda" (id. ibid., 181). A história do campo é produzida a partir de suas 
lutas internas. É o enfrentamento estabelecido frente à primazia das formas tradicionais de reconhecimento e de consagração - que, em geral, possuem seus instrumentos de legitimação já associados às regras asseguradas pela lógica das instituiçôes (em específico, o mercado de artes e as indústrias culturais). É nesse sentido que se faz necessária a produção e disseminação de uma illusio, por parte dos agentes novatos no campo (e que passam a ser reconhecidos como precursores e legitimados como porta-vozes de um novo movimento), baseada no valor da recriação a partir do que já existe como forma de legitimação de novos processos de criação e de consumo no campo cultural. Nesse contexto, os documentários, ao defenderem uma tese usando o próprio processo de criação como argumento, funcionam como instrumento de fortalecimento de uma illusio necessária às novas configuraçôes do campo.

\section{Referências bibliográficas}

BASTOS, Marcus. Remix como polifonia e agenciamentos coletivos. In: MARTINS, Camila D.; SILVA, Daniela C.; MOTTA, Renata (Orgs.) Territórios recombinantes. Arte e tecnologia - Debates e laboratórios. Cadernos Instituto Sergio Motta 13, Coleção Cultural. São Paulo: Imprensa Oficial do Estado de São Paulo, 2007. Disponível em: http://www.premiosergiomotta.org.br/diversos/d_550

BOURDIEU, Pierre. As regras da arte. São Paulo: Companhia das Letras, 1996.

BOURDIEU, Pierre. Coisas ditas. São Paulo, Brasiliense: 1990.

CASTRO, Gisela G. S. Pirataria na Música Digital: Internet, direito autoral e novas práticas de consumo. In: UNIrevista. Vol. 1, no 3, 2006. Disponível em http://www.unirevista.unisinos.br/_ pdf/UNIrev_Castro.PDF

CASTRO, Gisela. Para pensar o consumo da música digital. In: Revista FAMECOS. Porto Alegre, no 28, dezembro 2005. Disponível em: http://200.144.189.42/ojs/index.php/famecos/article/viewFile/448/375

JENKINS, Henry. Cultura da Convergência. São Paulo: Aleph, 2008.

LEMOS, André. Ciber-cultura-remix. Artigo apresentado no seminário "Sentidos e Processos" dentro da mostra "Cinético Digital', no Centro Itaú Cultural. São Paulo, Itaú Cultural, agosto de 2005. Disponível em: http:// www.facom.ufba.br/ciberpesquisa/andrelemos/remix.pdf

MACHADO, Arlindo. Arte e mídia. Rio de Janeiro: Jorge Zahar Ed., 2007.

MANOVICH, Lev. Language of new media. MIT Press, 2001.

NICHOLS, Bill. Representing reality. Bloomington and Indianapolis: Indiana University Press, 1991.

NICHOLS, Bill. Introdução ao documentário. Campinas, SP: Papirus, 2005.

RAMOS, Fernão Pessoa. Mas afinal... o que é mesmo documentário? São Paulo: Editora Senac São Paulo, 2008. 
SANTAELLA, Lucia. Culturas e artes do pós-humano. São Paulo: Paulus, 2003.

THOMPSON, Bill. Web 2.0: as conseqüências da tecnologia para a sociedade. In: VILLARES, Fábio (Org.) Novas mídias digitais. Audiovisual, games e música. Rio de Janeiro: E-papers, 2008.

\section{Notas}

1. Disponível em: http://www.youtube.com/watch?v=lcuDe4iGI6s Acesso em 19 de maio de 2013.

2. Disponível em http://www.rtve.es/television/documentales/copiad-malditos/ Acesso em 21 de setembro de 2012.

3. Disponível em http://www.youtube.com/watch?v=YY0i4xJss9c Acesso em 21 de setembro de 2012. 